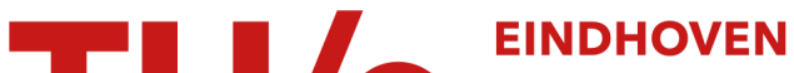 UNIVERSITY OF TECHNOLOGY
}

\section{Dynamic mechanical properties of anisotropic networks formed by liquid crystalline acrylates}

Citation for published version (APA):

Hikmet, R. A. M., \& Broer, D. J. (1991). Dynamic mechanical properties of anisotropic networks formed by liquid crystalline acrylates. Polymer, 32(9), 1627-1632. https://doi.org/10.1016/0032-3861(91)90398-3

DOI:

10.1016/0032-3861(91)90398-3

Document status and date:

Published: 01/01/1991

Document Version:

Publisher's PDF, also known as Version of Record (includes final page, issue and volume numbers)

Please check the document version of this publication:

- A submitted manuscript is the version of the article upon submission and before peer-review. There can be important differences between the submitted version and the official published version of record. People interested in the research are advised to contact the author for the final version of the publication, or visit the $\mathrm{DOI}$ to the publisher's website.

- The final author version and the galley proof are versions of the publication after peer review.

- The final published version features the final layout of the paper including the volume, issue and page numbers.

Link to publication

\section{General rights}

Copyright and moral rights for the publications made accessible in the public portal are retained by the authors and/or other copyright owners and it is a condition of accessing publications that users recognise and abide by the legal requirements associated with these rights.

- Users may download and print one copy of any publication from the public portal for the purpose of private study or research.

- You may not further distribute the material or use it for any profit-making activity or commercial gain

- You may freely distribute the URL identifying the publication in the public portal.

If the publication is distributed under the terms of Article $25 \mathrm{fa}$ of the Dutch Copyright Act, indicated by the "Taverne" license above, please follow below link for the End User Agreement:

www.tue.nl/taverne

Take down policy

If you believe that this document breaches copyright please contact us at:

openaccess@tue.nl

providing details and we will investigate your claim. 


\title{
Dynamic mechanical properties of anisotropic networks formed by liquid crystalline acrylates
}

\author{
R. A. M. Hikmet and D. J. Broer \\ Philips Research Laboratories, PO Box 80000, 5600JA Eindhoven, The Netherlands \\ (Received 23 January 1990; revised 12 June 1990; accepted 19 June 1990)
}

\begin{abstract}
Thermomechanical properties of oriented polymer networks, which had been obtained by photopolymerization of liquid crystalline acrylates, were investigated. The networks exhibited three mechanical loss peaks which were associated with the relaxation of the whole network, relaxation of the central aromatic unit of the molecules and the crankshaft motion of the methylene groups. Tensile modulus and the strength of the oriented networks were anisotropic and highly temperature dependent. The oriented networks also showed an anisotropic thermal behaviour, contracting in the direction of molecular orientation while expanding in the lateral directions with increasing temperature. The anisotropic properties of the oriented networks have been interpreted in terms of the molecular structure and grouping of the molecules formed after polymerization.
\end{abstract}

(Keywords: dynamic mechanical properties; anisotropic networks; liquid crystalline acrylates)

\section{INTRODUCTION}

Oriented polymeric structures are of great interest due to their special properties. Such structures can possess highly anisotropic optical, mechanical and electrical properties which are desirable for various applications. Numerous methods can be used to obtain oriented systems, including melt extrusion followed by drawing, gel drawing, solid-state extrusion, spinning of liquid crystalline (LC) systems etc. ${ }^{1,2}$. However, all these methods are less applicable when oriented coatings or films have to be produced on surfaces with complicated geometries and/or at high speeds, hence the suggestion of using low mass LC acrylates ${ }^{3-6}$. These molecules possess low viscosity and the orientation of the molecules can be achieved easily by a simple surface treatment ${ }^{7}$, by flow or in electric and magnetic fields. The induced orientation can subsequently be frozen in by isothermal photopolymerization of the system. In this paper the thermal and mechanical properties of networks formed by photopolymerization of LC acrylates are described. A homologous series of a liquid crystalline diacrylate was used, as shown in Figure 1.

\section{EXPERIMENTAL}

The structures of the monomers used for this study are shown in Figure 1. Details of the syntheses and polymerization of the monomers can be found in refs $3-6$. The monomers were provided with a $2 \% \mathrm{w} / \mathrm{w}$ photoinitiator, $\alpha, \alpha$-dimethoxydeoxybenzoin (Irgacure 651 Ciba Geigy). Oriented networks were obtained by sandwiching the monomer with $60 \mu \mathrm{m}$ spacers between two glass substrates provided with uniaxially rubbed polyethylene films. Uniaxially oriented samples were obtained when the rubbing directions of the substrates were parallel and twisted structures were obtained when they were perpendicular to each other. Polymerization of the materials was initiated by u.v. radiation from a $100 \mathrm{~W}$ high pressure mercury lamp $\left(366 \mathrm{~nm}, 3 \mathrm{~mW} \mathrm{~cm}^{-2}\right)$ in a nitrogen atmosphere where the sample temperature was regulated on a hot plate. Cells were subsequently opened and samples were removed and cut into strips $2 \mathrm{~mm}$ wide. Dynamic mechanical thermal analysis was carried out with a Polymer Laboratories DMTA apparatus. Loss tangent curves were obtained in the bending mode and the modulus measurements were carried out in the tensile mode. An Instron tensile tester was used for the stress-strain investigations and the thermal expansion behaviour of the samples was measured using a Perkin Elmer TMA7 unit.

\section{RESULTS AND DISCUSSION}

\section{Relaxation processes within the networks}

In Figure 2 loss tangent plots measured at $1 \mathrm{~Hz}$ for acrylates containing different numbers of methylene groups are shown. The existence of three loss peaks is quite apparent; these will be referred to as $\alpha, \beta, \gamma$ relaxations in order of decreasing temperature. It can also be seen that except for $\mathrm{C} 2$ the positions of $\beta$ and $\gamma$ relaxations remain almost constant as the $\alpha$ relaxation becomes broader and shifts to higher temperatures with decreasing number of methylene groups. This behaviour of the $\alpha$ peak is typical for crosslinked systems ${ }^{8,9}$ and it shows that the number of degrees of freedom to be frozen in, in order to reach the glassy state, decreases with increasing crosslink density and spreads over a wider temperature range. This effect is further demonstrated in Figure 3 where the loss tangent curves for polymerized mixtures of LC di- and monoacrylates are shown. With increasing diacrylate concentration (increasing crosslink density) the $\alpha$ relaxation peak shifts to higher temperatures and becomes broader.

An important factor, which plays a key role in the 
Monoacrylate

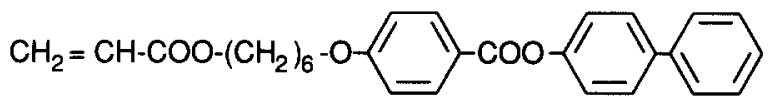

Diacrylates

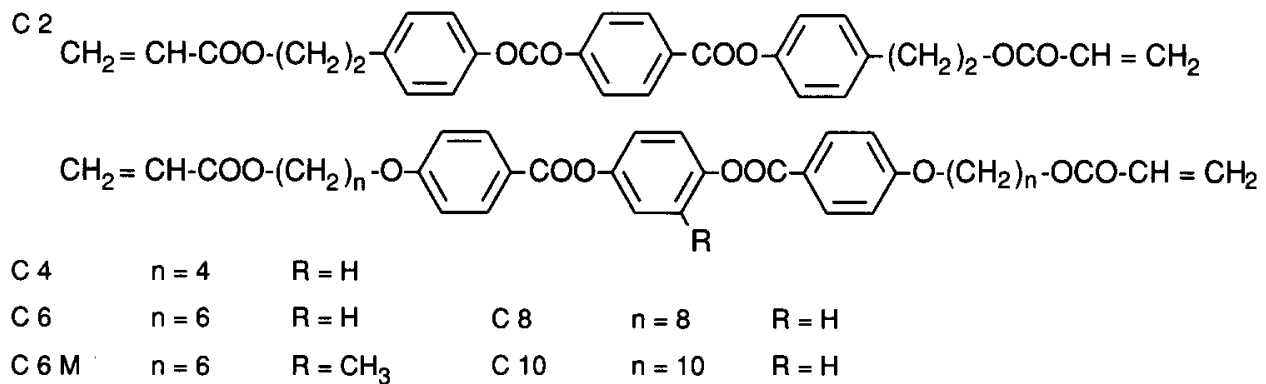

Figure 1 Molecular structure of the materials

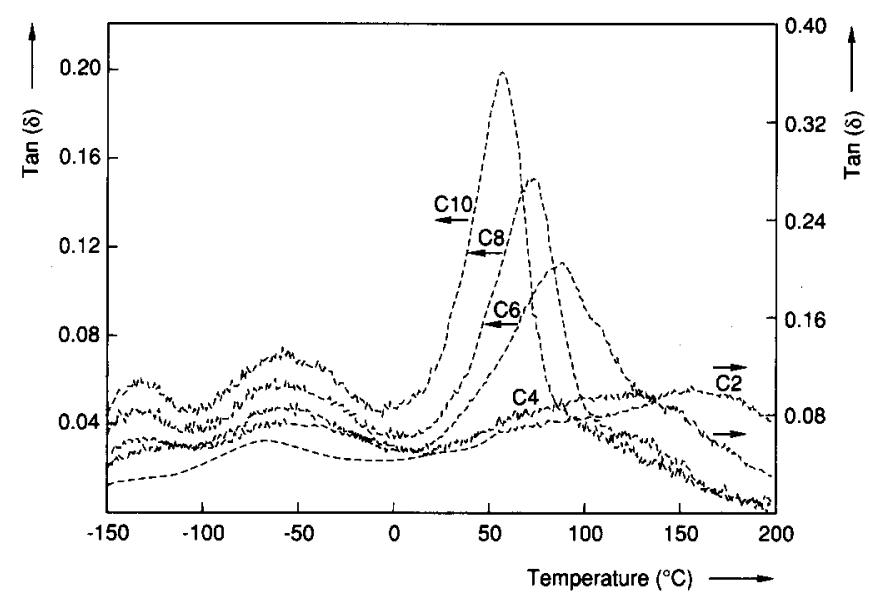

Figure 2 Loss tangent curves at $1 \mathrm{~Hz}$ for various fully polymerized networks

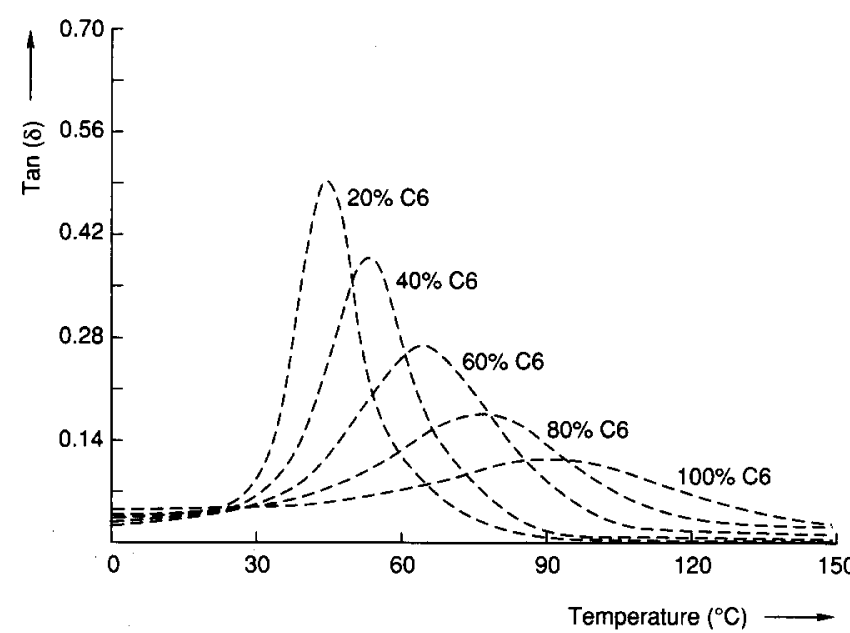

Figure 3 Loss tangent curves at $1 \mathrm{~Hz}$ for networks with various compositions of $\mathrm{C} 6$ and the monoacrylate

kinetic properties of the body, is the free volume. The free volume can be represented in terms of packing density $K$ (ref. 10) which is defined as:

$$
K=\frac{V_{\mathbf{w}}}{M / \rho}
$$

where $V_{w}$ is the van der Waals volume occupied by the atoms of a polymer repeat unit (using values from ref. $10), M$ is the molecular weight and $\rho$ is the density. In Table 1 the packing densities of molecules polymerized in liquid crystalline and isotropic states are given together with their room temperature densities and peak $\alpha$ transition temperatures measured at $1 \mathrm{~Hz}$. It can be seen that the packing density of the material polymerized in the liquid crystalline state is higher than in the isotropic state. However, this difference is quite small and the $K$ values obtained here for the oriented networks are of the same order as those for acrylate systems $(K=0.619$ $0.666)^{1}$ and lower than those for linear glassy polymers $(K=0.681 \pm 0.001)^{10}$ and those for epoxy-aromatic amine networks $(K=0.705-0.728)^{12}$. The low $K$ values obtained here can be associated with the steric hindrance caused by the packing of the rigid central aromatic unit. $X$-ray measurements ${ }^{13}$ suggest that on a small scale the molecules assume hexagonal packing with the estimated nearest neighbour distance in the order of $0.52 \mathrm{~nm}$. This distance, determined by the central rigid aromatic unit, limits the packing of the methylene units and consequently also the packing density within the system. Another interesting behaviour seen in Table 1 is the difference in the peak positions of the $\alpha$ transitions of the samples polymerized in the isotropic and LC states. It can be seen that even though the densities of the isotropic samples are lower, their loss tangent curves are shifted towards higher temperatures contrary to their free volumes. This behaviour cannot be associated with the difference of the degree of chemical crosslinking within the samples since in all cases the degree of conversion was higher than $95 \%$. It is interesting to consider physical crosslinks, which might explain the observed behaviour. Samples polymerized in the LC state contain mainly oriented units so that all the crosslinks within the samples are chemical in nature. In the case of the samples polymerized in the isotropic state physical crosslinks are expected to be present, in addition to the chemical crosslinks. Therefore it might be the existence of the physical crosslinks in the isotropic samples, putting extra constraint on the molecular motion, that causes the shift of the $\alpha$ transition peak to higher temperatures.

The transitions observed in Figure 2 can be characterized by a frequency dependence which can be described 
Table 1 Various properties of polymerized networks

\begin{tabular}{|c|c|c|c|c|c|c|c|c|c|c|}
\hline \multirow{3}{*}{$\begin{array}{l}\text { Property }^{a} \\
\text { State of } \\
\text { polymerization }\end{array}$} & \multicolumn{10}{|c|}{ Sample } \\
\hline & \multicolumn{2}{|r|}{$\mathrm{C} 4$} & \multicolumn{2}{|r|}{$\mathrm{C} 6$} & \multicolumn{2}{|c|}{$\mathrm{C} 6 \mathrm{M}$} & \multicolumn{2}{|r|}{$\mathrm{C} 8$} & \multicolumn{2}{|c|}{$\mathrm{C} 10$} \\
\hline & LC & I & $\mathrm{LC}$ & I & LC & I & LC & I & LC & I \\
\hline$\rho\left(\mathrm{g} \mathrm{cm}^{-3}\right)$ & 1.280 & 1.261 & 1.229 & 1.220 & 1.215 & 1.211 & 1.202 & 1.188 & 1.172 & 1.158 \\
\hline$K$ & 0.665 & 0.655 & 0.661 & 0.656 & 0.657 & 0.655 & 0.664 & 0.656 & 0.662 & 0.654 \\
\hline$T_{\alpha}\left({ }^{\circ} \mathrm{C}\right)$ & 118 & 124 & 83 & 91 & 83 & 91 & 71 & 82 & 55 & 58 \\
\hline$T_{\text {pol }}\left({ }^{\circ} \mathrm{C}\right)$ & 120 & 200 & 120 & 200 & 105 & 200 & 125 & 200 & 125 & 200 \\
\hline
\end{tabular}

${ }^{a} \rho=$ Density; $K=$ packing density; $T_{x}=$ peak $\alpha$ transition temperature; $T_{\mathrm{pol}}=$ polymerization temperature

Table 2 Activation energies from mechanical data

\begin{tabular}{lccc}
\hline & \multicolumn{3}{c}{ Activation energies $\left(\mathrm{kJ} \mathrm{mol}{ }^{-1}\right)$} \\
\cline { 2 - 4 } Sample & $\alpha$ & $\beta$ & $\gamma$ \\
\hline C4 & 378 & 83 & 58 \\
C6 & 357 & 86 & 56 \\
C6M & 360 & 124 & 56 \\
C8 & 344 & 80 & 56 \\
C10 & 315 & 80 & 55
\end{tabular}

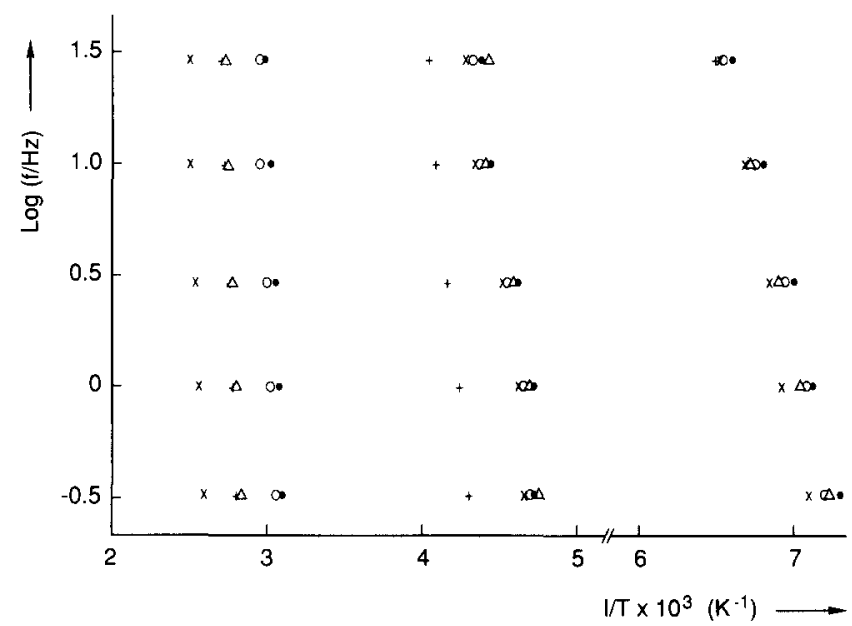

Figure $4 \log f$ versus $1 / T$ for $\alpha, \beta, \gamma$ relaxations measured for various samples. $\times, \mathrm{C} 4 ; \triangle, \mathrm{C} 6 ; \mathrm{O}, \mathrm{C} 8 ; \mathrm{C} 10 ;+, \mathrm{C} 6 \mathrm{M}$

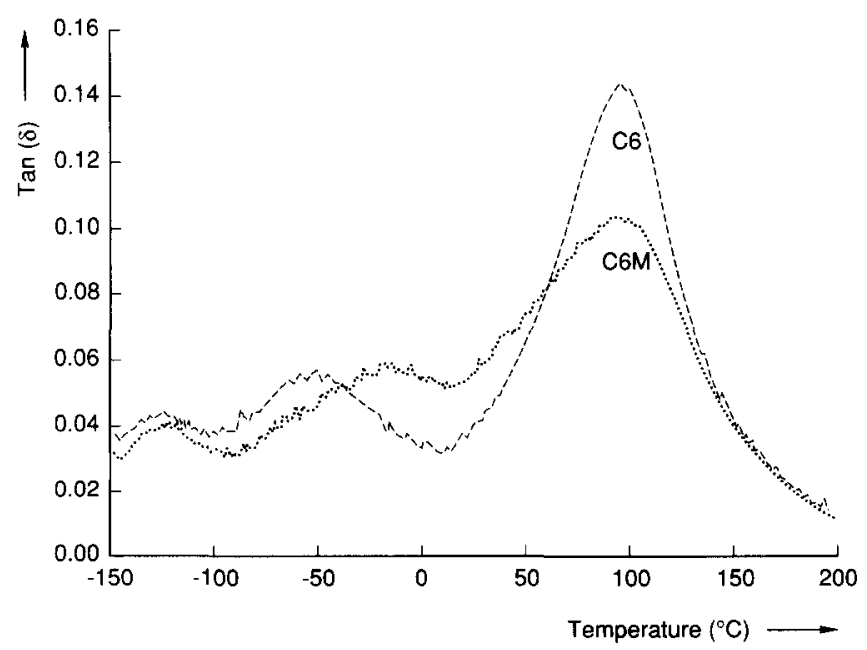

Figure 5 Loss tangent curves at $3 \mathrm{~Hz}$ for $\mathrm{C} 6$ and $\mathrm{C} 6 \mathrm{M}$ by an Arrhenius equation ${ }^{14}$. The various transitions undergone by the networks can be represented in a relaxation map, as shown in Figure 4, where $\log f$ is plotted against $1 / T$ for each transition. The calculated activation energies are summarized in Table 2.

As mentioned earlier, the $\alpha$ process with the highest activation energy is due to the relaxation of the whole network. Therefore the activation energy associated with this relaxation increases with increasing crosslink density of the system. The $\beta$ process is probably due to relaxation modes of the mesogenic unit since substitution of a methyl group into the central ring shifts the position of the $\beta$ peak by $30^{\circ} \mathrm{C}$ and causes an asymmetric broadening of the $\alpha$ and $\beta$ peaks, as seen in Figure 5, where the loss tangent curves of $\mathrm{C} 6$ and $\mathrm{C} 6 \mathrm{M}$ are compared. The substitution also increases the activation energy of the $\beta$ process, regardless of the decreased packing density of the system. This behaviour may be associated with the hindrance of the molecular motions by the presence of the bulky methyl group. Again the values obtained here for the activation energy of the $\beta$ relaxation are of the same order as those reported in the literature ${ }^{15-17}$.

The $\gamma$ transition can be associated with the crankshaft motion of $-\mathrm{CH}_{2}-$ groups. The intensity of the peak increases with increasing number of $-\mathrm{CH}_{2}-$ substitution. For $\mathrm{C} 2$, which has only two methylene groups in a row, the $\gamma$ peak becomes barely visible. This is in accordance with the results of Willbourn ${ }^{18}$ who suggested that the $\gamma$ relaxation can be attributed to a restricted motion of a chain which required at least four $-\mathrm{CH}_{2}-$ groups in succession and led to the crankshaft mechanism of Shatzki ${ }^{19}$ and Boyer $^{20}$. Furthermore the activation energy calculated here is in good agreement with the theoretical values of $40-60 \mathrm{~kJ} \mathrm{~mol}^{-1}$ (refs 19, 20).

\section{Mechanical properties}

Dynamic tensile moduli of the samples were measured at $1 \mathrm{~Hz}$ and $16 \mu \mathrm{m}$ peak-to-peak displacement using samples $3 \mathrm{~cm}$ long. Results of the measurements for various samples in the direction of molecular orientation are shown in Figure 6. All samples were polymerized at the same reduced temperature $\left(T / T_{\mathrm{c}}\right)$ of 0.94 to have the same order parameter. It can be seen that for all specimens there is a continuous fall in modulus over the whole temperature range. Figure 7 shows the tensile moduli of $\mathrm{C} 6$, in two major directions for a uniaxially oriented sample, in the direction perpendicular to the twist axis for a sample where the molecules are twisted $90^{\circ}$ from one surface to the other and also for an isotropic sample. It is clear that the modulus of the sample is very anisotropic. This behaviour is typical for oriented 


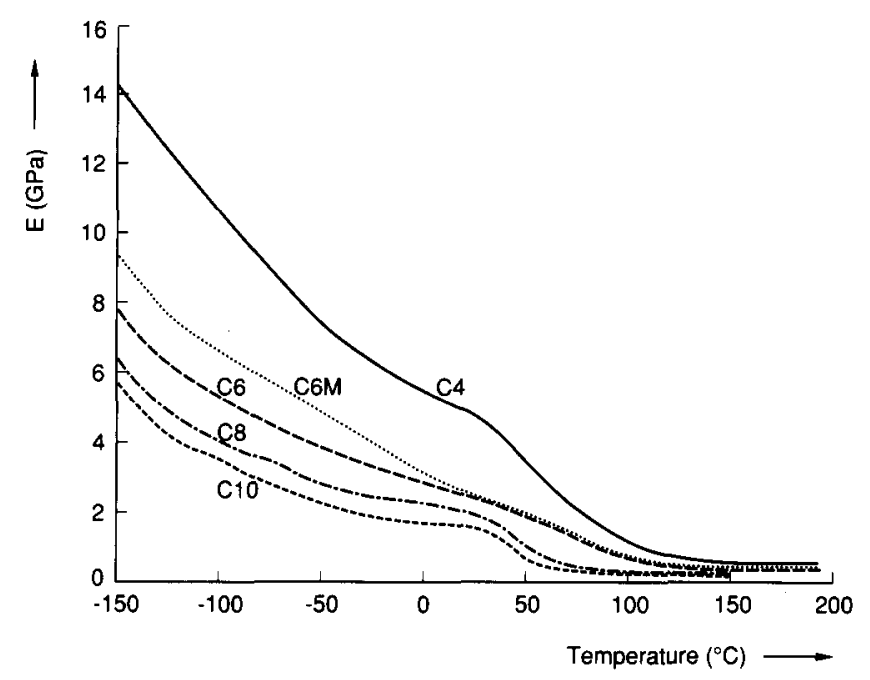

Figure 6 Dynamic tensile modulus at $1 \mathrm{~Hz}$ for various samples

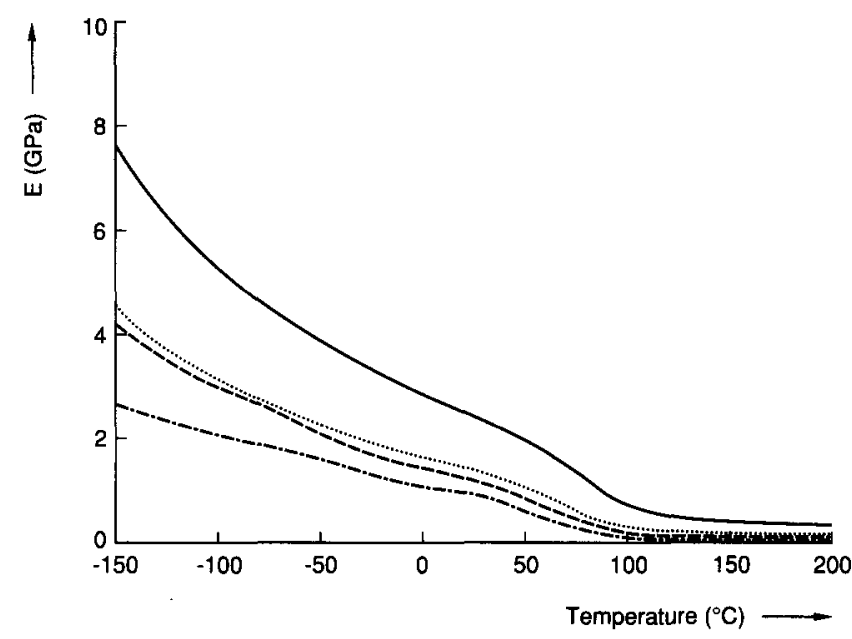

Figure 7 Dynamic tensile modulus at $1 \mathrm{~Hz}$ for $\mathrm{C} 6 . \longrightarrow$, Molecules oriented in the direction of strain; -.-.--, molecules perpendicular to the strain; ---, isotropic; $\cdots . .$. , twisted

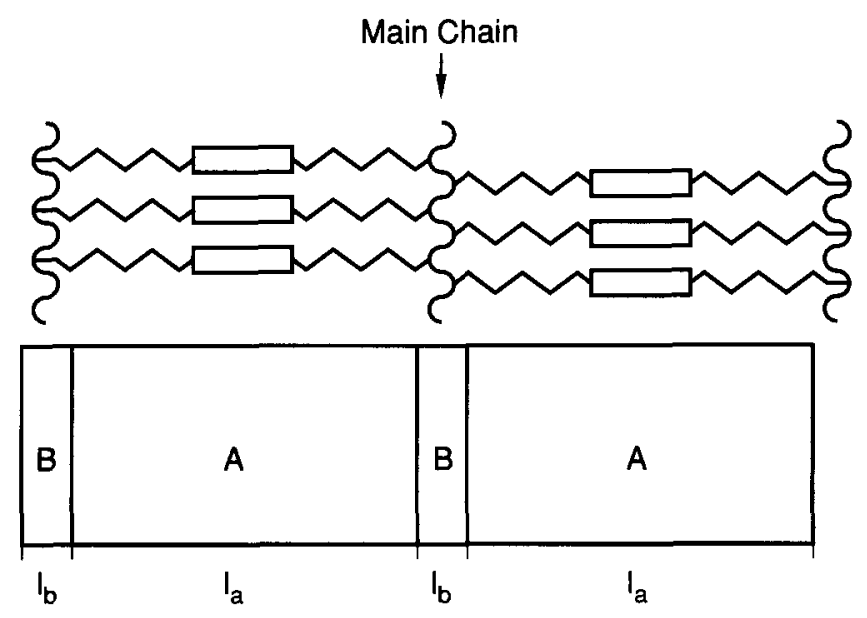

Figure 8 Schematic representation of a network unit

polymeric structures where higher values are observed for the tensile modulus, in the direction of molecular orientation than in perpendicular directions ${ }^{1,21}$. For the twisted and isotropic samples the modulus curves fall in between. However, the modulus values in the direction of molecular orientation observed here fall short of the values commonly observed for main chain LC polymers ${ }^{2}$.
This behaviour is explained well with the Takayanagi model $^{22}$ which was developed to account for the relaxation behaviour of two phase polymers, as recorded by dynamic mechanical testing. This model is used since for acrylate units to be able to react in the uniaxially oriented system they have to come within close proximity of each other. As a result two regions within the system are formed, as shown schematically in Figure 8. Suppose that region $A$ contains the oriented (aromatic and methylene) units and region B contains the acrylate main chain together with some of the methylene units. In the series arrangement of the units, for the case where the applied strain is in the direction of molecular orientation, the average modulus is given by:

$$
E^{\prime \prime}=\frac{l_{\mathrm{t}} E_{\mathrm{a}}^{\prime \prime} E_{\mathrm{b}}^{\prime \prime}}{l_{\mathrm{b}} E_{\mathrm{a}}^{\prime \prime}+l_{\mathrm{a}} E_{\mathrm{b}}^{\prime \prime}}
$$

where $E_{\mathrm{a}}^{\prime \prime}$ and $E_{\mathrm{b}}^{\prime \prime}$ are the moduli in the direction of the molecular orientation and $l_{\mathrm{a}}$ and $l_{\mathrm{b}}$ are the lengths of regions $\mathrm{A}$ and $\mathrm{B}$ respectively, and $l_{\mathrm{t}}=l_{\mathrm{a}}+l_{\mathrm{b}}$. In the case of parallel arrangement of the regions, for the case where the applied strain is perpendicular to the direction of molecular orientation, the average modulus of the system is given by:

$$
E^{\perp}=\frac{l_{\mathrm{a}} E_{\mathrm{a}}^{\perp}+l_{\mathrm{b}} E_{\mathrm{b}}^{\perp}}{l_{\mathrm{t}}}
$$

where $E_{\mathrm{a}}^{\perp}$ and $E_{\mathrm{b}}^{\perp}$ are the moduli in the direction perpendicular to the molecular orientation.

From equations (2) and (3) it can be seen that the measured modulus is a function of the moduli and the volume fractions of the two regions. Region $\mathrm{A}$, which contains the oriented units, is expected to have a higher modulus in the direction of orientation than region $B$, which contains the acrylate main chain. Therefore it can be seen that the existence of regions $B$ in series with regions $\mathrm{A}$ can decrease the total modulus considerably as compared with pure $A$. It is interesting to note that, according to equation (2), as the fraction of the oriented units increases the total modulus should also increase. However, it is found (Figure 6) that across the whole temperature range the modulus decreases with increasing length of LC molecules. This means that the modulus of region A decreases with increasing $-\mathrm{CH}_{2}-$ units. Perfectly aligned parallel molecules in an all trans conformation are expected to give high values for the modulus since deformation will primarily involve bending and stretching of covalent bonds. However, here we have a situation where the molecules are not perfectly aligned, as a result of which molecules are also subjected to shear forces. The effect of the order parameter on the modulus of $\mathrm{C} 6$ acrylate is given in Table 3. It can be seen that the tensile modulus in the direction of orientation increases with increasing degree of order. In Table 3 order parameters

Table 3 Tensile modulus and order parameters of $\mathrm{C} 6$ polymerized at various temperatures

\begin{tabular}{llll}
\hline & \multicolumn{3}{c}{$\begin{array}{c}\text { Polymerization temperature } \\
\left({ }^{\circ} \mathrm{C}\right)\end{array}$} \\
\cline { 2 - 4 } & 145 & 120 & 90 \\
\hline Order parameters, $S$ & 0.6 & 0.62 & 0.73 \\
Tensile modulus, $E(\mathrm{GPa})$ & 2.2 & 2.2 & 2.4 \\
\hline
\end{tabular}


$(S)$ of $\mathrm{C6}$ were estimated from the equatorial arcs obtained from X-ray measurements using the following equation:

$$
S=\frac{1}{2}\left(3 \cos ^{2} \theta-1\right)
$$

where $\theta$ is the mean angle of incline of the molecules. However, in Figure 6 the magnitude of the shearing is expected to be similar for all samples since they were all polymerized at the same reduced temperature to have the same order parameter. The decrease in modulus with increasing flexible $-\mathrm{CH}_{2}$ - units is therefore probably due to conformational irregularities within these units. Due to these irregularities, tensile deformation involves rotation around bonds as well as bending of bonds, hence the decrease in the modulus. Therefore in the modelling in Figure 8 a large part of the flexible units should also be included in regions $B$.

The effect on the modulus due to the methyl group substitution to the central ring is also demonstrated in Figure 6. It can be seen that the moduli of $\mathrm{C} 6$ and $\mathrm{C} 6 \mathrm{M}$ are similar up to around $20^{\circ} \mathrm{C}$. Below this temperature a higher value for the modulus is observed for $\mathrm{C} 6 \mathrm{M}$ than for $\mathrm{C} 6$. This behaviour is probably due to the $\beta$ relaxation which sets in at higher temperatures for C6M than for C6 due to the methyl substitution. As a result, the modulus of $\mathrm{C} 6 \mathrm{M}$ begins to increase earlier and higher values of modulus are observed for $\mathrm{C} 6 \mathrm{M}$ than for $\mathrm{C} 6$ at low temperatures.

\section{Fracture behaviour of the networks}

The stress-strain behaviour of the networks was tested at a strain rate of $2 \% \mathrm{~min}^{-1}$ and results are shown in Figure 9. In Figure $9 a$ the stress-strain behaviour of the C6 polymer at different temperatures is shown. The polymer shows brittle failure at all temperatures and the tensile strength decreases with increasing temperature. Deformation behaviour and the mechanical behaviour of the networks depend on their state. In the rubbery state the chemical structure and the topology of the network are the key factors in determining the fracture process. In the glassy state, however, the type and number of defects determine the fracture behaviour ${ }^{12}$.

In Figure $9 b$ the stress-strain behaviour at room temperature is shown for $\mathrm{C} 6$ with different orientations. When the sample is strained in the direction parallel to molecular orientation brittle fracture is observed. When the strain is applied in the direction perpendicular to the

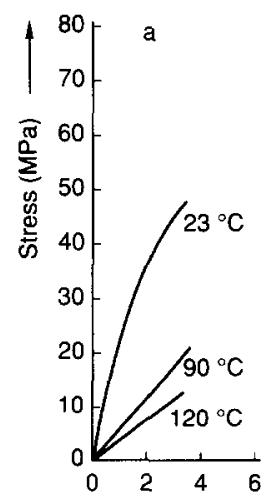

Strain $(\%)$

Figure 9 Stress-strain curves for (a) $\mathrm{C} 6$ at various temperatures; (b) $\mathrm{C} 6$ at $23^{\circ} \mathrm{C}$ with various orientation; (c) various samples at $23^{\circ} \mathrm{C}$

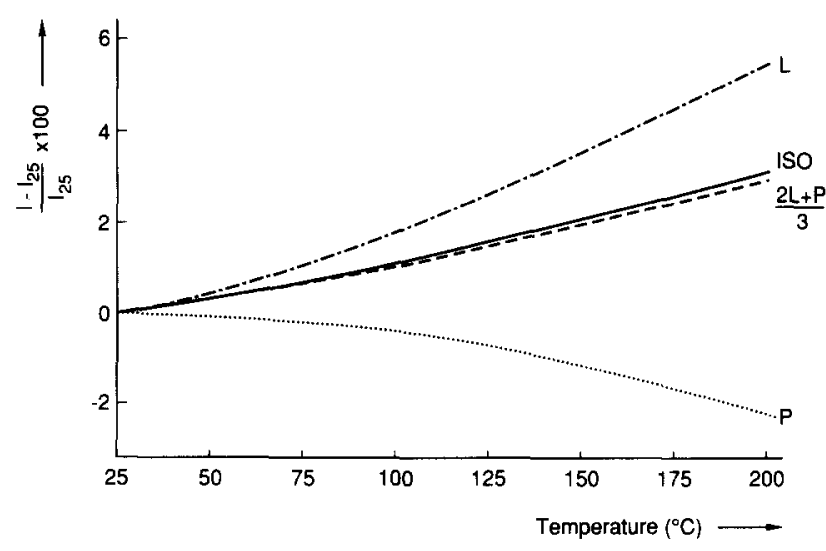

Figure 10 Linear thermal expansion for $\mathrm{C} 6 . \ldots \ldots$, In the direction of molecular orientation $(P) ;-\cdot-\cdot-$, in the direction perpendicular to molecular orientation $(L) ;-$, isotropic;--- average $((2 L+P) / 3)$

molecular orientation, the stress reaches a maximum value at which it remains constant before decreasing slightly to reach failure. This might be described as ductile. For isotropic and twisted samples the stress and strain values at break were found to be between those for parallel and perpendicular samples.

In Figure $9_{c}$ the stress-strain behaviour of samples strained in the direction of molecular orientation is shown for various samples. It is seen that the maximum stress and strain at failure decreases with increasing number of $-\mathrm{CH}_{2}-$ units. The failure mechanism in the glassy state is strongly related to the defects which cause stress concentrations within the system ${ }^{12}$. Therefore as these defects are expected to be in areas confining the acrylate main chain, the tensile strength is expected to increase with decreasing volume of defect regions (in this case, with increasing number of $-\mathrm{CH}_{2}-$ units). However, the opposite behaviour is observed here. Therefore the fracture processes within these systems are more complex and must also be associated with the distribution and size of the regions containing the main chain as well as the glass transition temperature of the system.

\section{Thermal expansion}

In Figure 10 the linear thermal expansion of $\mathrm{C} 6$ is shown in two major directions for a sample polymerized in the LC state together with the linear expansion for the sample polymerized in the isotropic state. It is seen that in the direction parallel $(P)$ to the orientation the thermal expansion coefficient of the molecules is lower than in the lateral $(L)$ directions. This behaviour is typically observed for oriented polymeric systems. The low expansion coefficient below the $\alpha$ transition temperature is attributed to the covalent bonding of the molecules, whereas above the $\alpha$ transition temperature shrinkage is caused due to the higher mobility within the oriented system. The average linear expansion of the sample polymerized in the LC state, calculated as $(2 L+P) / 3$, is compared with the expansion of the isotropic sample. Here it can be seen that despite the differences in the packing densities of the two samples, they show expansion coefficients which are very similar in the glassy state. At higher temperatures, however, a slightly higher expansion of the isotropic sample could be observed. This shows that even though the $\alpha$ peak for the isotropic sample appears at a higher temperature, 
both samples show a very similar volume expansion regardless of the conformation and relative arrangement of the molecules.

\section{CONCLUSIONS}

It has been shown that LC acrylates can be polymerized in the anisotropic state to obtain structures with anisotropic mechanical properties. The LC acrylates used in this study exhibited three mechanical loss peaks which are associated with various relaxation mechanisms within the system. The main relaxation peak, $\alpha$, related to the relaxation of the whole network, shifted to lower temperatures with increasing flexible spacer length of the acrylate molecule. The position of the $\alpha$ transition temperature also depended on the phase of polymerization and shifted to higher temperatures when the samples were polymerized in the isotropic state, showing the effect of relative arrangement and packing of the molecules on their relaxation behaviour. The $\beta$ and $\gamma$ peaks were associated with the relaxation of the central aromatic unit and the crankshaft motion of the methylene units respectively. The network modulus was found to be anisotropic and highly temperature dependent. Furthermore the tensile modulus showed a prominent dependence on the length of the methyl chain and decreased with increasing number of methylene units. The tensile strength of the networks was also found to be anisotropic. In the direction of chain orientation brittle fracture was observed and in the direction perpendicular to chain orientation ductile failure was observed. Anisotropic samples also showed anisotropic expansion behaviour. However, both isotropic samples and samples polymerized in the LC state showed very similar volume expansion behaviour.

\section{REFERENCES}

1 Ward, I. M. 'Mechanical Properties of Solid Polymers', Wiley Interscience, New York, 1983

2 Zachariades, A. E. and Porter, R. S. 'The Strength and Stiffness of Polymers', Marcel Dekker Inc., New York, 1983

3 Broer, D. J., Finkelmann, H. and Kondo, K. Makromol. Chem. 1988, 189, 185

4 Broer, D. J., Boven, J., Mol, G. N. and Challa, G. Makromol. Chem. 1989, 190, 2255

5 Broer, D. J., Hikmet, R. A. M. and Challa, G. Makromol. Chem 1989, 190, 3202

6 Broer, D. J., Mol, G. N. and Challa, G. Makromol. Chem. in press

7 Priestly, E. B., Wojtowicz, P. J. and Sheng, P. 'Introduction to Liquid Crystals', Pendulum Press, London, 1974, Ch. 12

8 Kloosterboer, J. G. and Liften, G. F. C. M. in 'Biological and Synthetic Polymer Networks' (Ed. O.Kramer), Elsevier Applied Science, 1986

9 Suzuki, Y., Fujimoto, T., Tsunada, S. and Shibayama, K. $J$ Macromol. Sci. 1980, B17 (4), 787

10 Bondi, A. 'Physical Properties of Molecular Crystals, Liquids and Glasses', John Wiley, New York, 1968

11 Kloosterboer, J. G. Polym. Commun. in press

12 Dusek, K. in 'Advances in Polymer Science' (Ed. K. Dusek), Springer-Verlag, Berlin, 1986

13 Hikmet, R. A.M. and Broer, D. J. in 'Integration of Fundamental Polymer Science and Technology' (Eds L. A. Kleintjes and P. Lemstra), Elsevier Applied Science, London, 1989

14 Ferry, J. D. 'Viscoelastic Properties of Polymers', 3rd Edn, Wiley Interscience, New York, 1980

15 Troughton, M. J., Davies, G. R. and Ward, I. M. Polymer 1989, 30,58

16 Monnerie, L., Lauperetre, F. and Noel, C.Liquid Crystals 1988, 3, 1013

17 Zentel, R., Strobl, G.R. and Ringsdorf, H. Macromolecules 1985 , 18, 960

18 Willbourn, A. H. Trans. Faraday Soc. 1960, 54, 717

19 Shatzki, J. Polym. Sci. 1962, 57, 496

$20 \quad$ Boyer, R. F. Rubber Rev. 1963, 34, 1303

21 Wright, H., Faraday, C. S. N., White, E. F. T. and Treloar, L. R. G. J. Phys. D 1971, 4, 2002

22 Takayanagi, M., Imada, K. and Kajiyama, T. J. Polym. Sci. C $1966,15,263$ 